\title{
СМЕШАННЫЕ УГОЛОВНЫЕ ТРИБУНАЛЫ: НОВЫЙ ВИД ПРАВОСУДИЯ?
}

\begin{abstract}
Аннотация. В статье речь идет о смешанных уголовных трибуналах, которые по мнению автора являются уголовными трибуналами третьего поколения. Исследуется история создания классических международных уголовных судов. Смешанные трибуналы, или «гибридные», или «интернационализированные», представляются собой институты в которых соединяются международные судебные учреждения, и судебные институции той страны, где были совершены соответствующие преступления; в этих трибуналах действуют иностранные (их часто называют международными) и начиональные судьи, а в статутах встречаются нормы и международного и национального права. Автор считает, что первостепенной причиной создания смешанных уголовных трибуналов является неэффектиивность и национальных, $u$ международных уголовных судов в расследовании международных преступлений. Смешанные трибуналы - достаточно гибкая форма предъявления ответственности в тех случаях, когда с помощью иных средств ничего достичь невозможно. Они достаточно гибкие и могут быть приспособлены к разным обвиняемым и разным деяниям.
\end{abstract}

Ключевые слова: международное право, уголовное право, национальное право, судебная система, смешанный суд, наииональный суд, международный суд, эффективность, гибрид, международные преступления.

Abstract: The article concerns mixed criminal tribunals, which in the opinion of the author represent the third generation criminal tribunals. The author studies the history of formation of the classic international criminal courts. The mixed ("hybrid", "internationalized") tribunals are the institutions, combining international legal institutions and the judicial institutions of the state, where the relevant crimes were committed. These tribunals involve foreign (they are often called international) and national judges, and their statutes also include norms of both national and international law. The author considers that the primary cause for the formation of mixed criminal tribunals is inefficiency of both national and international criminal tribunals in the investigation of international crimes. The mixed tribunals represent a rather flexible form for guaranteeing due responsibility in the cases, when no other matters may achieve results. They are rather flexible and they may work with various criminal defendants and various criminal acts.

Keywords: international law, criminal law, national law, judicial system, mixed court, national court, international court, efficiency, hybrid, international crimes.

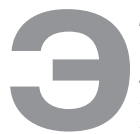

ти суды называют «уголовными трибуналами третьего поколения»: сначала были Нюрнбегский и Токийский трибуналы, затем трибуналы по бывшей Югославии и Руанде, а также Международный уголовный суд. Это, пожалуй, самая динамично развивающаяся часть международной судебной системы.

Первым опытом создания международных уголовных трибуналов были Нюрнбегский и Токийский трибуналы, работавшие после второй мировой войны для суда над военными преступниками. 45 лет спустя были созданы два международных уголовных трибунала $a d$ hoc - трибунал по бывшей Югославии и Трибунал для Руанды. Они были так же беспрецедентны, как и послевоенные трибуналы, не получили всеобщего признания, и не породили множества подражаний. Основными причинами, по которым международные уголовные суды - Трибуналы для Югославии и Руанды не могут оцениваться как полностью успешные, обычно называют их широкий масштаб, медлительность и дороговизну. Они нанимают большое число персонала, а также обнаруживают тенденцию выходить из- 
под контроля своих создателей, что диктуется логикой развития внутреннего права международной организации. Практика Международного уголовного суда показывает, что ему не могут быть представлены все случаи международных преступлений из-за ограниченного признания его юрисдикции государствами ${ }^{1}$.

Но в мировом сообществе ощущалась потребность в разработке мер ответственности для военных преступников, для преступлений против человечности и геноцида. Поэтому на свет появилась новая категория судов, носящих в определенной степени экспериментальный характер - так называемые смешанные трибуналы. Их еще называют «гибридными», или «интернационализированными», поскольку в них соединяются международные судебные учреждения, и судебные институции той страны, где были совершены соответствующие преступления. Эти трибуналы отличаются и от национальных и от международных судебных учреждений. В них, как правило, действуют иностранные (их часто называют международными) и национальные судьи, а в статутах встречаются нормы и международного и национального права. Таких судебных учреждений прежде не существовало.

В последние годы был создан целый ряд таких судов. Специальные жюри для тяжелых преступлений в Окружном суде Дили (Восточный Тимор), действовавшие в 2000 - 2005 гг., Жюри по «Правилам 34 и 64» в судах Косова (действуют с 2000 г.); Специальный суд для Сьерра-Леоне (действует с 2002 г.); Палата по военным преступлениям Конституционного суда Боснии-Герцеговины (действует с 2005 г.)

Три других смешанных суда находятся в различных стадиях подготовки: Чрезвычайная палата в судах Камбоджи; Специальная палата в судах Бурунди; Смешанный трибунал для расследования в отношении лиц, ответственных за убийство бывшего Премьер-министра Ливана Рафика Харири и 22 других человека ${ }^{2}$.

\footnotetext{
${ }^{1}$ Sriram C.L. Globalising Justice: From Universal Jurisdiction to Mixed Tribunals//Northern Quaterly of Human Rights, v.22, 2004, p.12.

${ }^{2}$ Обзор см.: Romano C. Mixed Jurisdictions for East Timor, Kosovo, Sierra Leone and Cambodia: The Coming of Age of Internationalized Criminal Bodies?// The Global Community: Yearbook of International Law and Jurisprudence. v. 2, 2002, p.97-138.
}

С формальной точки зрения в качестве смешанного трибунала можно рассматривать и Иракский чрезвычайный трибунал, хотя в нем не было представлено иностранных судей, в противоречие его собственному статуту. Кроме того, им применяется только иракское право.

Не вполне международным уголовным трибуналом является Палата Конституционного суда Боснии-Герцеговины, скорее это суд по правам человека, поскольку она применяет договоры о правах человека, а не международное уголовное право.

Первостепенной причиной создания смешанных уголовных трибуналов является неэффектиивность и национальных, и международных уголовных судов в расследовании международных преступлений.

Хотя теоретически именно национальные суды - наиболее подходящее место для расследования уголовных преступлений, лишь отдельные государства располагают необходимыми средствами для организации процесса в отношении международных преступлений, в частности, для защиты его участников; власти государств часто не склонны проводить такие процессы по политическим соображениям.

Юридическая природа смешанных уголовных трибуналов отражает обстоятельства создания каждого из них. В Косове и на Восточном Тиморе все государственное управление было сосредоточено в руках $\mathrm{OOH}$, в том числе правосудие, уголовное и гражданское. Советом Безопасности ООН была создана Администрация переходного периода для Восточного Тимора Резолюцией 1272 от 25 октября 1999г. ${ }^{3}$, и Миссия ООН в Косове Резолюцией 1244 от 10 июня 1999 г. $^{4}$, во главе которых стояли Специальные представители Генерального секретаря с полномочиями, определенными Советом Безопасности. В частности, в задачу обеих миссий входило воссоздание жизнеспособной, справедливой и вызывающей доверие судебной системы. В Восточном Тиморе эта система должна была создаваться с чистого листа, после уходе индонезийских войск; в Косове стояла трудная задача наказания военных преступников

\footnotetext{
${ }^{3}$ United Nations Transitional Administration in East Timor $<$ http://www.un.org/peace/etimor/UntaetN.htm>

${ }^{4}$ United Nations Interim Administration Mission in Kosovo $<$ http://www.unmikonline.org $>$
} 
в судах, где доминировали албанцы, которые считали себя пострадавшими от этих преступников. Специальные представители Генерального секретаря на обеих территориях издали постановления о создании специальных жюри в судах, действуя в пределах своего мандата. На Восточном Тиморе Постановлением 2000/11 было предусмотрено создание одного апелляционного суда в столице Дили, и восьми районных судов, наделенных уголовной и гражданской юрисдикцией. Для рассмотрения «серьезных» преступлений было предусмотрено специальное Жюри в составе Районного суда Дили.

В Косове правовая база была создана двумя постановлениями: по постановлению 2000/34 международные судьи и обвинители могут участвовать в любом деле в суде, к которому они приписаны, в любом случае, когда считают это необходимым для обеспечения правосудия. Однако установлено, что серьезные преступления слушаются жюри в составе двух профессиональных судей и трех асессоров (судей, не являющихся профессиональными юристами). Постановлением 2000/64 было дополнительно указано, что обвинитель, обвиняемый или защитник могут просить о назначении в состав судебного присутствия трех судей, включая двух международных судей, один из который станет председателем. С течением времени большая часть дел стала заслушиваться именно в таком составе.

Палата по военным преступлениям Конституционного суда Боснии-Герцеговины - это особенный случай. Ее правовую базу составляет набор соглашений: Общее рамочное соглашение о мире в Боснии-Герцеговине, известное как Дейтонское соглашение, в соответствии с которым создан пост Высокого представителя (он же Специальный представитель Европейского союза) для контроля за имплементацией гражданских аспектов мирного урегулирования, включая систему правосудия; соглашение между Высоким представителем и правительством Боснии-Герцеговины о создании специального Департамента военных преступлений; соглашение между Высоким представителем и Международным трибуналом по бывшей Югославии о передаче дел из МТБЮ в югославский суд; Резолюция Совета Безопасности ООН 1503 от 26 сентября 2003г. о создании Палаты по военным преступлениям.
В других случаях правительство соответствующего государства сохраняет суверенную власть на своей территории. Первостепенная цель при этом - обеспечить осуществление правосудия, а наказание преступников отходит на второй план. В этом случае международное сообщество не может своей властью создать судебную систему, и местные власти должны быть участником переговоров о формировании механизмов уголовной ответственности. Правовой основой становится международный договор между правительством и, как правило, ООН. Целью создаваемых здесь уголовных трибуналов является, прежде всего, наказание преступников. Так, в смешанных уголовных трибуналах для Сьерра-Леоне, Камбоджи и Бурунди юрисдикция ratione personae ограничена теми лицами, кто несет самую большую ответственность за нарушение местных законов и международного гуманитарного права, то есть политическими и военными лидерами. В случае Восточного Тимора, Косова и БоснииГерцеговины упор делается не на командиров, а на низший эшелон армии и администрации.

Сроки действия юрисдикции смешанных судов иногда вызывают вопросы. Так, оказалось непросто определить начало действия юрисдикции Специального суда для Сьерра-Леоне в процессе переговоров о его создании. Гражданская война в этой стране длилась почти 10 лет (с 1991 до 2001), к власти поочередно приходили разные силы и заключались коротко живущие соглашения. Было решено, что Суду подсудны только деяния, совершенные после 30 ноября 1996г., когда было заключено Абиджанское соглашение между правительством страны и Объединенным революционным фронтом. Дата была выбрана потому, что именно тогда были приняты реальные меры мирного урегулирования 5 .

Что касается Восточного Тимора, юрисдикция жюри по серьезным преступлениям не имеет ограничений во времени. Однако на деле все обвинения, заслушанные жюри, относятся к периоду перед и сразу после выводы индонезийских войск в 1999 г.

\footnotetext{
${ }^{5}$ Agreement between the United Nations and the Government of Sierra Leone on the Establishment of a Special Court for Sierra Leone (adopted 16 January 2002, entered into force 12 April 2002) 2178 UNTS 137.
} 
Юрисдикция же Трибунала Харири сосредоточена на одном событии - массовом убийстве 14 февраля 2005 г. Однако Резолюция Совета Безопасности 1644 от 15 декабря 2005 г., которая предписывала Генеральному Секретарю оказать содействие правительству Ливана «установить суть и объем необходимой международной помощи в деле расследования» дает возможность распространить полномочия созданной в рамках $\mathrm{OOH} \mathrm{Независимой} \mathrm{международной} \mathrm{комиссии}$ расследования на все террористические атаки в Ливане с 1 октября 2004 г. ${ }^{6}$

Юрисдикция Палат для Камбоджи ограничена преступлениями, совершенными между 17 апреля 1975 г. и 6 января 1979 г. то есть с момента занятия столицы страны армией Красных кхмеров до момента освобождения ее Вьетнамской армией․ Однако на самом деле насилие и гражданская война длилась в Камбодже гораздо дольше, почти до 1991 г.

Особенность смешанных трибуналов - это участие граждан страны, затронутой насилием. В трибуналах для Руанды или Югославии мы не найдем ни одного из их граждан, выступающего в качестве судьи или обвинителя.

Участие граждан в процессе создает несколько благоприятных последствий. Так, среди местного населения создается чувство доверия к их правосудию. С другой стороны, иностранный персонал может служить гарантией беспристрастности и качественного разбирательства, поскольку смешанные суды большей частью действуют в странах, где судебная система разрушена. Конечно, здесь встает вопрос о балансе. Обычно иностранцы составляют большинство судебного присутствия. Обвинитель и секретарь суда - также обычно иностранцы, а защитник - местный.

В Специальном суде для Сьерра Леоне судей-международников всегда большинство. Трое из них служат в Следственной палате, один из них назначается правительством страны, а два -

\footnotetext{
${ }^{6}$ UNSC Res 1644 (15 December 2005) UN Doc S/RES/1644.

${ }^{7}$ Draft Agreement between the United Nations and the Royal Government of Cambodia concerning the Prosecution under Cambodian Law of Crimes Committed during the Period of the Democratic Kampuchea (adopted by the UN General Assembly 13 May 2003) UN Doc A/Res/57/228b.
}

Генеральным секретарем ООН. Пять судей состоят в Апелляционной палате, причем двое из них назначаются правительством страны, а три других - Генеральным секретарем ООН. Приговор выносится большинством голосов всех судей.

В Косове ситуация более сложная. Иностранные судьи могут составлять и большинство, и меньшинство присутствия, в зависимости от того, по какому постановлению Высокого представителя создается жюри.

В Палате по военным преступлениям в БоснииГерцеговине баланс не остается неизменным. Сначала жюри составлялось из двух иностранных судей и одного национального, который являлся также председателем. Постепенно ситуация изменилась, число иностранных судей сокращалось, и ныне их там нет.

Очень любопытно решен вопрос о составе Чрезвычайной палаты в Камбодже. Иностранные судьи, будучи в меньшинстве, и персонал не имеют фактического контроля над Палатой. Временное соглашение между ООН и Королевским правительством Камбоджи относительно наказания, по камбоджийскому праву, преступлений, совершенных в период Демократической Кампучии, предусматривает параллельную систему, состоящую из Следственной палаты и Верховного суда, действующего как апелляционный орган и конечная инстанция. Следственные палаты формируются из пяти профессиональных судей (трех камбоджийцев и двух иностранцев). В любом случае председательствует камбоджиец.

Однако камбоджийские судьи лишены возможности навязывать свою волю иностранцам. Все решения должны приниматься большинством голосов (четырьмя из пяти в Следственной палате и пять из семи в Верховном суде). Это дает иностранным судьям возможность блокировать решения. Более того, в случае отсутствия единства, в текст решения включаются точки зрения большинства и меньшинства. Предусмотрено наличие двух обвинителей: одного камбоджийца и одного иностранца. Предполагается, что они должны совместно разрабатывать обвинение. Если же между ними возникнет разногласие, любой из них может просить о разрешении спора палатой из пяти судей (три камбоджийца и два иностранца); решение принимается большинством в четыре голоса из пяти. 
Важным вопросом любого судебного разбирательства является вопрос о применимом праве. Смешанные трибуналы применяют смешанное национальное и международное материальное и процессуальное право. Состав его не одинаков в разных судах и в разных случаях. В целом можно сказать, что основу применимого права составляет национальное право страны, где трибунал образован. Но оно обычно изменяется, приспосабливается, дополняется нормами международного права с целью сформировать одобряемые международным сообществом стандарты прав человека и стандарты уголовного разбирательства. Если необходимо изменить местное законодательство, именно местные власти (либо международная организация, контролирующая территорию) осуществляет необходимые изменения в соответствии с требованиями местной конституции.

Смешанные трибуналы применяют ту часть обычного и договорного международного права, которая относится к преступлениям, предусмотренным международным правом, в тех случаях, когда сталкивается с такими преступлениями. В этом смешанные трибуналы не отличаются от международных уголовных трибуналов.

Могут быть случаи, когда смешанный трибунал наделен юрисдикцией над международными преступлениями, которые являются преступлениями не по общему международному праву, а лишь по какому-либо отдельному договору (как, например, преступление пытки в случае Восточного Тимора; или разрушение культурных ценностей во время внутреннего вооруженного конфликта в Камбодже); или ему приходится соблюдать некие процессуальные стандарты, налагаемые основными договорами по правам человека. Если государство, в котором работает смешанный трибунал, является участником такого договора, или если содержание такого договора отражает обычное международное право, и в той степени, в какой применимый договор не просто содержит определение состава или смутного стандарта, ему придется применять и такой договор. В остальном же применимым будет национальное право.

При этом смешанный уголовный трибунал остается частью национальной судебной системы, и для него применение международного права составляет такую же проблему, как для любого национального уголовного суда.

Учредительные документы смешанных трибуналов далеко не всегда регулируют эту проблему. Так, в Восточном Тиморе Постановление Высокого представителя, которым создан Трибунал, говорит: право Восточного Тимора применяется Трибуналом в той степени, в какой оно не препятствует исполнению мандата ООН и не противоречит постановлениям Высокого представителя или распоряжениям Администрации переходного периода ${ }^{8}$; еще одно постановление дополняет: жюри по особо тяжким преступлениям применяет, где это надлежит сделать, договоры и признанные принципы и нормы международного права, в том числе принципы международного права, применимые к вооруженному конфликту 9 . Это дает свободу жюри в опоре на международное право.

Соответствующее постановление Высокого представителя в Косове имеет почти такое же содержание. Правда, в нем нет разъяснения о соотношении международного права и национального уголовного права в случае конфликта: в Косове жюри должны решать проблемы соответствия норм международного права действующему косовскому праву, сообразуясь с обстоятельствами каждого дела.

Специальный суд в Сьерра Леоне, базирующийся на соглашении между этой страной и $\mathrm{OOH}$, явно не составляет часть судебной системы страны, и его статут отдает приоритет в применении международному праву.

Чрезвычайные палаты в Камбодже решают вопросы взаимодействия между международным и национальным правом в соответствии с принципами своего конституционного устройства.

Поскольку смешанные трибуналы составляют часть судебной системы государства ${ }^{10}$, встает вопрос о соотношении юрисдикции этих

\footnotetext{
${ }^{8}$ UNTAET Reg. 1999/1 [27 November 1999] UN Doc UNTAET/ REG/1999/1, Sec. 3

9 UNTAET Reg. 2000/15 [6 June 2000] UN Doc UNTAET/ REG/2000/15, Sec. 3.1

${ }^{10}$ Хотя и не все. Например, Специальный суд для Сьерра Леоне, в соответствии со своим учредительным актом (Special Court Agreement Ratification Act of 2002.) не входит в судебную систему страны.
} 
трибуналов и национальных судов. Обладают ли национальные суды компетенцией на рассмотрение дел, находящихся преимущественно в юрисдикции смешанных трибуналов? Вправе ли индивид обжаловать законность образования смешанного трибунала в национальном суде? Может ли национальный суд пересмотреть решение смешанного трибунала? Возможно ли судебное преследование лица национальным судом, если его дело уже рассматривалось смешанным трибуналом и наоборот? Каково юридическое значение решения трибунала для национальных судов?

Во всех этих вопросах прослеживаются до некоторой степени те же проблемы, которые стоят в плане взаимоотношений национальных и международных судов. Однако есть и различия.

В целом смешанные трибуналы существуют отдельно от национальных судов. Их юрисдикция de jure или de facto имеет исключительный характер. Только в отдельных случаях национальные суды могут вмешиваться в дела, подлежащие юрисдикции смешанного трибунала. В тех случаях, когда юрисдикции смешанных судов и судов общей юрисдикции частично совпадают, трибуналу предоставлен приоритет; полномочия национальных судов в части пересмотра создания смешанного трибунала или пересмотра решения смешанного уголовного трибунала в лучшем случае ограничена. Приговор смешанного уголовного трибунала в принципе препятствует разбирательству национального суда по тому же делу. Однако полного разделения полномочий между национальными судами и смешанными уголовными трибуналами нет.

Следует уделить внимание также и проблеме отношений смешанных уголовных трибуналов с государствами иными, чем в которых они действуют, а также с международными организациями.

Проблемы в сотрудничестве с третьими государствами могли бы встать, прежде всего, в трибуналах по Восточному Тимору и Косову. В обоих этих случаях жюри наделены полномочиями решением Совета Безопасности и в определенной степени опираются на его полномочия. Все члены $\mathrm{OOH}$ обязаны с ними сотрудничать. Однако на практике решение вопросов задержания и выдачи обвиняемых из Индонезии и Албании соответственно, оказалось нелегким делом.

Проблемы неизбежны в Сьерра Леоне и Камбодже, а также, возможно, в Бурунди и Ливане, где смешанные трибуналы создаются на основе соглашений между их правительствами и ООН. Во всех этих случаях активную роль играет Совет Безопасности, однако формально они не могут опираться на его полномочия. Если третьи государства будут отказываться передавать своих подозреваемых смешанному трибуналу, отсутствие прямого указания Совета Безопасности приведет к юридическим неясностям, которые могут затормозить весь процесс. Подобный пример дает попытка задержать бывшего президента Либерии Чарльза Тейлора.

Что касается взаимоотношений между смешанными уголовными трибуналами и международными уголовными судами, то здесь определяющим фактором является положение смешанного трибунала в конституционном порядке соответствующего государства ${ }^{11}$. Например, уголовные жюри в Косове являются частью судебной системы Косова, то есть это национальные суды. Международный трибунал по бывшей Югославии обладает приоритетом перед национальными судами, и может вмешиваться в национальные процедуры расследования, включая и рассмотрение дела уголовными жюри, на любой стадии, если это необходимо в интересах международного правосудия. Но над смешанным трибуналом в Сьерра Леоне суд, подобный Трибуналу по Югославии, не может иметь приоритет, поскольку смешанный трибунал в этой стране не является частью ее судебной системы.

Юрисдикция Международного уголовного суда дополняет юрисдикцию национальных судов. Так, если международное преступление совершается, например, в Косове, МУС не может рассматривать это дело вместо уголовного жюри. Нет ясности о его полномочиях в тех случаях, когда его юрисдикция может пересекаться с юрисдикцией смешанных трибуналов.

Отдельный случай - Палата по военным преступлениям в Боснии-Герцеговине. Ее

\footnotetext{
${ }^{11}$ Dickinson L. The Relationship between Hybrid Courts and International Courts: The Case of Kosovo//American Journal of International Law, v.97, 2003, p. 309.
} 
создание было частью общего пересмотра национальной судебной системы. Как часть этой системы Палата осуществляет высшую юрисдикцию в отношении самых серьезных военных преступлений, совершенных в Боснии-Герцеговине, в то время как «рядовые» военные преступления рассматриваются кантональными и районными судами. Однако есть мнения о том, что Палата задумывалась как вспомогательное учреждение Трибунала по Югославии ${ }^{12}$. Мандат Палаты состоит в следующем: расследование преступлений персонала низшего и среднего звена, передаваемых Трибуналу по Югославии по Правилам процедуры и сбора доказательств Трибунала. Дела, рассмотрение которых не завершено, передаются Палате Канцелярией прокурора Трибунала; применяются также так называемые «дорожные правила», которые были первоначально разработаны как отклик на опасения относительно произвольных арестов и задержаний после окончания войны в Боснии-Герцеговине. По этим правилам от властей Боснии требовалось, прежде чем произвести арест, представить любое дело о военном преступлении в Канцелярию Прокурора для установления достаточности доказательств с точки зрения международных стандартов. Ясно, что для эффективной работы Палаты ей необходимо тесное сотрудничество с Трибуналом по Югославии.

Таким образом, в настоящее время пока еще трудно однозначно оценить эффективность смешанных уголовных трибуналов. Пока только специальные жюри для серьезных преступлений на Восточном Тиморе закончили свою работу. Смешанные жюри в Косове и БоснииГерцеговине, а также Специальный суд для Сьерра Леоне еще действуют; Чрезвычайные палаты в Камбодже, Специальный трибунал для Бурунди и Трибунал по убийству Харири пока еще не приступили к работе ${ }^{13}$.

\footnotetext{
12 Strohmeyer H. Collapse and Reconstruction of a Judicial System: The United Nations Missions in Kosovo and East Timor// AJIL (2001), v. 95, p. 46.

${ }^{13}$ Linton S. Cambodia, East Timor and Sierra Leone: Experiments in International Justice //Criminal Law Forum, v.12, 2011,p. 185
}

За пять лет Жюри на Восточном Тиморе предъявили 95 обвинений 391 человеку, 84 были осуждены и 3 оправданы. Генеральным секретарем ООН была создана комиссия для оценки их деятельности, которая констатировала, что цель полностью не достигнута и в качестве причин назвала недостаточное финансирование, неполную независимость Канцелярии Генерального прокурора правительства Восточного Тимора, а также помехи, чинившиеся Индонезией ${ }^{14}$.

В выводах комиссии суммированы особенности, характерные для всех смешанных трибуналов: их невысокая стоимость - привлекательная черта, но это снижает эффективность; смешанные трибуналы, как правило, испытывают большие затруднения в контактах с местными властями, третьими странами и международными организациями; между иностранными и местными судьями в составе трибуналов сотрудничество не бывает легким: к различиям в культуре и образовании, а также в оплате, имеет значение и сознание того, что иностранцы уедут после завершения работы, а местные судьи останутся ${ }^{15}$.

Конечный вывод Комиссии состоял в том, что смешанный трибунал для Восточного Тимора работал бы эффективнее, если бы он был создан Советом Безопасности по Главе VII Устава ООН и базировался в третьей стране; либо их функции следовало бы исполнять Международному уголовному суду.

Однако не следует забывать о том, что вряд ли юрисдикция Международного уголовного суда будет когда-нибудь признана всеми государствами, так что он станет «всемирным» уголовным судом.

Кроме того, смешанные трибуналы - достаточно гибкая форма предъявления ответственности в тех случаях, когда с помощью иных средств ничего достичь невозможно. Они достаточно гибкие и могут быть приспособлены к разным обвиняемым и разным деяниям.

\footnotetext{
${ }^{14}$ Report to the Secretary General of the Commission of Experts to Review the Prosecution of Serious Violations of Human Rights in Timor-Leste (then East Timor) in 1999 (24 June 2005) UN Doc S/2005/458.

${ }^{15}$ Romano C., Nollkaemper A., Kleffner J. (eds) Internationalized Criminal Courts and Tribunals: Sierra Leone, East Timor, Kosovo, and Cambodia. Oxford, 2004.
} 


\section{Библиография:}

1. Dickinson L. The Relationship between Hybrid Courts and International Courts: The Case of Kosovo// American Journal of International Law, v.97, 2003, p. 309.

2. Linton S. Cambodia, East Timor and Sierra Leone: Experiments in International Justice //Criminal Law Forum, v.12, 2011,p. 185

3. Sriram C.L. Globalising Justice: From Universal Jurisdiction to Mixed Tribunals//Northern Quaterly of Human Rights, v.22, 2004, p.12.

4. Strohmeyer H. Collapse and Reconstruction of a Judicial System: The United Nations Missions in Kosovo and East Timor//AJIL (2001), v. 95, p. 46.

5. Romano C. Mixed Jurisdictions for East Timor, Kosovo, Sierra Leone and Cambodia: The Coming of Age of Internationalized Criminal Bodies?// The Global Community: Yearbook of International Law and Jurisprudence. v. 2, 2002, p.97-138.

6. Romano C., Nollkaemper A., Kleffner J . (eds) Internationalized Criminal Courts and Tribunals: Sierra Leone, East Timor, Kosovo, and Cambodia. Oxford, 2004.

7. Г.Г. Шинкарецкая. Изъятие из компетенции судебных учреждений дел, относящихся к внутренней компетенции государства // Право и политика. - 2010. - № 3.

8. Г.Г. Шинкарецкая. Запрет злоупотребления международной судебной процедурой как фактор обеспечения судебного процесса // Право и политика. - 2010. - № 2.

9. Р.А. Каламкарян, Ю.И. Мигачев. Всеобщая Декларация прав человека: роль и значение в условиях миропорядка на основе господства права Rule of Law. // Право и политика. - 2008. - № 12. - С. 104-107.

10. Р.А. Каламкарян. Всеобщая декларация прав человека-60 лет. Позитив международно-правового опыта. // Право и политика. - 2008. - №

11. Ерпылева Н.Ю. Международный коммерческий арбитраж: правовые основы функционирования // NB: Международное право. - 2013. - № 1. - C.1-74. DOI: 10.7256/2306-9899.2013.1.545. URL: http://enotabene.ru/wl/article_545.html

12. Р. А. Каламкарян. Международный уголовный суд. // Право и политика. - 2002. - № 6. Каламкарян P.А. Роль Международного Суда ООН в деле поддержания международного правопорядка // NB: Международное право. - 2013. - № 1. - C.184-214. DOI: 10.7256/2306-9899.2013.1.690. URL: http://enotabene.ru/wl/article_690.html

13. Каламкарян Р.А. Включенность Российской Федерации в деятельность Международного Суда $\mathrm{OOH}$ в деле обеспечения международной законности и правопорядка // NB: Международное право. - 2013. - № 2. - C.85-118. DOI: 10.7256/2306-9899.2013.2.691. URL: http://e-notabene.ru/wl/ article_691.html

14. Кузьмина Ю.А. Некоторые особенности практики Европейского Суда в отношении Российской Федерации // NB: Международное право. - 2013. - № 3. - C.68-87. DOI: 10.7256/2306-9899.2013.3.2424. URL: http://e-notabene.ru/wl/article_2424.html

15. Ранчинская П.О.. Специфика взаимодействия российского и международного права в области международного коммерческого арбитража // Право и политика. - 2013. - № 10. - С. 104-107. DOI: 10.7256/1811-9018.2013.10.9581.

16. А.С. Смбатян. Перспективы суда ЕврАзЭС в системе органов международного правосудия // Международное право и международные организации / International Law and International Organizations. - 2013. - № 1. - C. 104-107. DOI: 10.7256/2226-6305.2013.01.7.

17. Р. А. Каламкарян. Международный суд ООН как административно-правовой орган мирового сообщества по мирному разрешению международных споров // Международное право и международные организации / International Law and International Organizations. - 2011. - № 2

18. Сазонова К.Л. К вопросу о соотношении международных преступлений государства, норм јus cogens и обязательств erga omnes в современном международном праве // Право и политика. 2013. - 9. - C. 1175 - 1181. DOI: 10.7256/1811-9018.2013.9.9410. 
19. Р. А. Гурбанов Европейская судебная сеть и Евроюст как основные субъекты сотрудничества органов правосудия государств-членов ЕС в сфере уголовного правосудия. // Международное право и международные организации / International Law and International Organizations. - 2011. - 4. - C. $113-120$.

20. В. А. Оганесян Решения международных судов по правам человека как особый источник развития и соблюдения принципов уголовного правосудия // Международное право и международные организации / International Law and International Organizations. - 2012. - 1. - C. 65 - 71.

\section{References (transliteration):}

1. Dickinson L. The Relationship between Hybrid Courts and International Courts: The Case of Kosovo// American Journal of International Law, v.97, 2003, p. 309.

2. Linton S. Cambodia, East Timor and Sierra Leone: Experiments in International Justice //Criminal Law Forum, v.12, 2011,p. 185

3. Sriram C.L. Globalising Justice: From Universal Jurisdiction to Mixed Tribunals//Northern Quaterly of Human Rights, v.22, 2004, p.12.

4. Strohmeyer H. Collapse and Reconstruction of a Judicial System: The United Nations Missions in Kosovo and East Timor//AJIL (2001), v. 95, p. 46.

5. Romano C. Mixed Jurisdictions for East Timor, Kosovo, Sierra Leone and Cambodia: The Coming of Age of Internationalized Criminal Bodies?// The Global Community: Yearbook of International Law and Jurisprudence. v. 2, 2002, p.97-138.

6. Romano C., Nollkaemper A., Kleffner J . (eds) Internationalized Criminal Courts and Tribunals: Sierra Leone, East Timor, Kosovo, and Cambodia. Oxford, 2004.

7. G.G. Shinkaretskaya. Iz"yatie iz kompetentsii sudebnykh uchrezhdenii del, otnosyashchikhsya k vnutrennei kompetentsii gosudarstva // Pravo i politika. - 2010. - № 3.

8. G.G. Shinkaretskaya. Zapret zloupotrebleniya mezhdunarodnoi sudebnoi protseduroi kak faktor obespecheniya sudebnogo protsessa // Pravo i politika. - 2010. - № 2.

9. R.A. Kalamkaryan, Yu.I. Migachev. Vseobshchaya Deklaratsiya prav cheloveka: rol' i znachenie v usloviyakh miroporyadka na osnove gospodstva prava Rule of Law. // Pravo i politika. - 2008. - № 12. - S. 104-107.

10. R.A. Kalamkaryan. Vseobshchaya deklaratsiya prav cheloveka-60 let. Pozitiv mezhdunarodno-pravovogo opyta. // Pravo i politika. - 2008. - №

11. Erpyleva N.Yu. Mezhdunarodnyi kommercheskii arbitrazh: pravovye osnovy funktsionirovaniya // NB: Mezhdunarodnoe pravo. - 2013. - № 1. - S.1-74. DOI: 10.7256/2306-9899.2013.1.545. URL: http://e-notabene.ru/wl/article_545.html

12. R. A. Kalamkaryan. Mezhdunarodnyi ugolovnyi sud. // Pravo i politika. - 2002. - № 6. Kalamkaryan R.A. Rol' Mezhdunarodnogo Suda OON v dele podderzhaniya mezhdunarodnogo pravoporyadka // NB: Mezhdunarodnoe pravo. - 2013. - № 1. - S.184-214. DOI: 10.7256/2306-9899.2013.1.690. URL: http://e-notabene.ru/wl/article_690.html

13. Kalamkaryan R.A. Vklyuchennost' Rossiiskoi Federatsii v deyatel'nost' Mezhdunarodnogo Suda OON v dele obespecheniya mezhdunarodnoi zakonnosti i pravoporyadka // NB: Mezhdunarodnoe pravo. - 2013. - № 2. - S.85-118. DOI: 10.7256/2306-9899.2013.2.691. URL: http://e-notabene.ru/wl/article_691.html

14. Kuz'mina Yu.A. Nekotorye osobennosti praktiki Evropeiskogo Suda v otnoshenii Rossiiskoi Federatsii // NB: Mezhdunarodnoe pravo. - 2013. - № 3. - S.68-87. DOI: 10.7256/2306-9899.2013.3.2424. URL: http://e-notabene.ru/wl/article_2424.html

15. Ranchinskaya P.O.. Spetsifika vzaimodeistviya rossiiskogo i mezhdunarodnogo prava v oblasti mezhdunarodnogo kommercheskogo arbitrazha // Pravo i politika. - 2013. - № 10. - S. 104-107. DOI: 10.7256/1811-9018.2013.10.9581. 
16. A.S. Smbatyan. Perspektivy suda EvrAzES v sisteme organov mezhdunarodnogo pravosudiya // Mezhdunarodnoe pravo i mezhdunarodnye organizatsii / International Law and International Organizations. - 2013. - № 1. - S. 104-107. DOI: 10.7256/2226-6305.2013.01.7.

17. R. A. Kalamkaryan. Mezhdunarodnyi sud OON kak administrativno-pravovoi organ mirovogo soobshchestva po mirnomu razresheniyu mezhdunarodnykh sporov // Mezhdunarodnoe pravo i mezhdunarodnye organizatsii / International Law and International Organizations. - 2011. - № 2

18. Sazonova K.L. K voprosu o sootnoshenii mezhdunarodnykh prestuplenii gosudarstva, norm jus cogens i obyazatel'stv erga omnes v sovremennom mezhdunarodnom prave // Pravo i politika. 2013. - 9. - C. 1175 - 1181. DOI: 10.7256/1811-9018.2013.9.9410.

19. R. A. Gurbanov Evropeiskaya sudebnaya set' i Evroyust kak osnovnye sub"ekty sotrudnichestva organov pravosudiya gosudarstv-chlenov ES v sfere ugolovnogo pravosudiya. // Mezhdunarodnoe pravo i mezhdunarodnye organizatsii / International Law and International Organizations. - 2011. - 4. - C. $113-120$.

20. V. A. Oganesyan Resheniya mezhdunarodnykh sudov po pravam cheloveka kak osobyi istochnik razvitiya i soblyudeniya printsipov ugolovnogo pravosudiya // Mezhdunarodnoe pravo i mezhdunarodnye organizatsii / International Law and International Organizations. - 2012. - 1. - C. $65-71$. 